\title{
Nacionalismo, globalizaciones y la sociedad chilena ${ }^{1}$
}

\section{Claudio Véliz}

La revolución indusirial trajo como consecuencia la movilidad social, que tuvo efectos destructivos sobre los valores sociales y morales. Se pasó de la comunidad estrecha a asociaciones puntuales, mtativas, substitutas de la comunidad traitcional. Aunque se habla mucho de "olobalización", en los hechos hoy existe una mayor cantidad de naciones que nunca. La homogenización, como resultado de una supuesta globalización, también es una falacia. Durante el siglo XX predominó un pragmatismo político internacional que invariablemente valoro lo que se percibe como interés naciomal por sobre aquel de un villorrio universal en gestación. El autor propone que sólo ma opción nacionalista con la necesmia autoridad moral, vinculada a la nacionalidad, puede contribuir al establecimiento de nuevos patrones de cohestón social, acordes con las necesidades y oporthmidades que ofrece la modemidad industrial. Esta nueva opción nacionalista of freceria mejores esperanzas que la globalización.

No hay periodo más pródigo que el siglo diecinueve en cuanto a interpretaciones de la historia y la sociedad y predicciones acerca del futuro de la condición humana. La explicación de esta abundancia extraordinaria no es misteriosa. Las décadas de Comte, Ranke, Burckhardt, Marx, Spencer, Durkheim y Toennies fueron asimismo las del fructífero encuentro entre las certezas científicas y tecnológicas acumuladas desde la revolución intelectual del siglo diecisiete, y las trágicamente postergadas esperanzas del siglo de las luces. Pareció entonces a muchos que si se llevara al estudio de la historia y la sociedad la metodología científica que tan buen éxito había tenido en el campo de las ciencias naturales, se obtendrían resultados igualmente alentadores. La consecuencia fue una notable proliferación de idearios reformistas,

\footnotetext{
- Texto basado en la Clase Magistral ofrecida el 19 de octubre de 1999, en la Casa Central de la Universidad Diego Portales, durante la celebración del dếcimo séptimo aniversario de la fundación de la casa de estudios.
} 
revolucionarios, reaccionarios, utópicos, demenciales y, algunas veces, sensatos, plausibles y perceptivos, bajo cuyas banderas ha marchado gran parte de nuestra humanidad durante las sombrías décadas del siglo veinte.

En aquella enorme aglomeración de ideas, programas e interpretaciones se destacan un gran acierto y un gran error que reclaman ser considerados cuando se reflexiona acerca de los desafíos, las limitaciones y las posibles consecuencias del proceso cultural que la prensa ha decidido denominar "globalización", así como acerca de su compleja relación con los nacionalismos americanos en general y en especial con el nuestro.

El gran acierto se refiere a la apreciación de los efectos destructivos que la movilidad social necesariamente asociada con el avance de la modemidad industrial ejercía entonces, y continúa haciéndolo hoy día, tanto sobre la comunidad tradicional como sobre sus valores sociales y morales ${ }^{2}$. Aún cuando no fueron muchos los estudiosos de la sociedad decimonónica que no se percataron de esta impredecible consecuencia del proceso modernizador, fue Ferdinand Toennies quien mejor y de modo más duradero encapsuló el proceso, acuñando los ahora famosos aunque intraducibles términos Gemeinschaft y Gesellschaft, con que nuestro siglo veinte se ha acostumbrado a expresar la transición de la comunidad pre-industrial a las asociaciones características d la modernidad ${ }^{3}$. Lo medular de estos dos conceptos es que los seres humanos pertenecemos a las comunidades tradicionales -Gemeinschaft-no obstante todos los factores que tiendan a separarnos, mientras que en el caso de las asociaciones modernas de corte Gesellschaft, cualquiera de los esfuerzos que hagamos por ligarnos íntimamente a ellas, basta darse media vuelta y mandarse cambiar para desligarse. Ejemplos de las primeras son, por supuesto, la familia, el lenguaje, la religión y el terruño natal, mientras las asociaciones Gesellschaft están bien representadas por clubes deportivos, gremios, sociedades anónimas, hermandades políticas y asociaciones profesionales.

\footnotetext{
2 La movilidad social a que me refiero fue entonces y sigue siendo hoy día, una consecuencia inevitable e irreversible de una revoluciốn industrial cuyos avances científicos, nuevas aplicaciones tecnológicas e impredecibles repercusiones culturales exigen reajustes permanentes de los factores de producción incluyendo, desde luego, el factor trabajo. Por ejemplo, los cambios en las preferencias de los consumidores - la apertura o cerrazón de mercados demandan nuevas combinaciones y localizaciones geográficas de los factores de producción, tales como aquellos obviamente asociados con la instalación de salmoneras en Chiloê, la plantaciôn de frutales en el Norte Chico o el desmantelamiento de fabricas textiles en Santiago. ${ }^{3}$ Ferdinand Toennies, (1955-1936), Gemeinschaft und Gesellschaft, Leipzig, 1987; editada en inglēs bajo el titulo, Fundamental Concerpts of Sociology, traducción de C.P. Loomis, New York, 1940.
} 
Esta percepción de lo ocurrido acarreó consigo la decidora reafirmación del imperativo social que desde luego los albores de la humanidad estableció la adscripción a grupos sociales como definitiva de la condición humana. Se comprendió asimismo que esta continuidad social data desde los más lejanos orígenes del género humano, y que durante los muchos milenios que transcumieron hasta el advenimiento de la modemidad industrial, nuestros antepasados nacieron, vivieron y murieron rodeados de congéneres que les eran perfectamente familiares. Incluso las grandes migraciones e invasiones bárbaras fueron traslaciones masivas de pueblos enteros que incluían no sólo la clase guerrera, sino que asimismo sus mujeres e hijos, sirvientes, esclavos, animales, cosechas y utensilios. La ordenación social de los hunos, cuando estos residían en las estepas asiáticas era tan estrechamente comunitariaGemeinschaft- como lo fue más adelante, una vez instalados en las riberas del Amo, del Ródano, o del Danubio.

En tales circunstancias, la vergüenza, el miedo al deshonor, y sanciones como el exilio o la exclusión de participar en ocasiones rituales, que durante milenios fueron factores decisivos en la mantención del andamiaje moral y espiritual de la sociedad, dependían necesariamente del vigor de las comunidades Gemeinschaft. En las agrupaciones tradicionales todos se conocían y las excepciones atraían la comprensible suspicacia del grupo, puesto que aparte de los embajadores, peregrinos y mercaderes, los pocos forasteros que muy de vez en cuando aparecían por esos mundos eran fugitivos de la justicia, bandidos, o soldados en busca de botín de guerra.

El sociólogo estadounidense Peter Berger afirma que modernidad es vivir rodeado por gente que uno no conoce. Siendo esto así, no sorprende verificar que frente a la disolución de la sociedad tradicional de corte Gemeinschaft y el desmantelamiento de sus estructuras comunitarias morales y afectivas, el ingenio humano haya generado una multitud de substitutos y paliativos del tipo Gesellschaft, incluyendo clubes sociales, partidos políticos y hermandades secretas, sociedades de aficionados a jugar con trenes eléctricos, la crianza de perros y palomas mensajeras, la jardinería y la filatelia, amén de una infinidad de conjuntos artísticos y musicales, agrupaciones religiosas de nuevo cuño y, por supuesto, abrumadoramente, el deporte moderno.

Casi sin excepción quienes practican los deportes modernos, especialmente los de equipo, así como los millones de espectadores de tales ejercicios, encuentran tanto su origen como la explicación de su auge y popularidad ac- 
tuales no en la antigüedad greco-romana, sino que en la abrumadora demanda social por paliativos plausibles para los indeseables efectos sociales y morales a que ha dado origen la Revolución Industrial. Deportes tales como el fútbol, rugby, basketball y volleyball fueron inventados y alentados con una clara intención moral y socializante. El fútbol y el rugby, por ejemplo, nacieron al abrigo de Rugby School, en Inglaterra, bajo la tutela del famoso Dr. Thomas Arnold, quien estaba convencido que la práctica de estos deportes contribuiría decisivamente a robustecer el carácter y la entereza moral de sus alumnos. Más adelante, especialmente en la Inglaterra de las primeras décadas de la industrialización, la entusiasta participación de jugadores y espectadores en encuentros semanales, especialmente en las regiones industriales, tuvo un papel importante en la urgente búsqueda de substitutos de la desaparecida comunidad tradicional. No está de más recordar aquí que el basketball y el voleyball fueron inventados en 1891 y 1895 respectivamente en las Asociaciones Cristianas de Jóvenes (YMCA) de Springfield y Holyoke, en Massachusetts, con el bien definido objeto de vigorizar la vida moral de sus miembros alentándoles a practicar deportes durante los largos inviernos de la Nueva Inglaterra, cuando las bajísimas temperaturas hacían imposible los ejercicios al aire libre. ${ }^{4}$

Estas entidades de algo han servido para atenuar los desconcertantes efectos de la desaparición de las estructuras normativas tradicionales, pero evidentemente sin posibilidades reales y duraderas de llenar el vacío que dejan tras de sí hábitos de conducta moral, comprensión y cooperación, lealtades filiales y regionales forjados al través de los muchos milenios de convivencia social que precedieron la irrupción revolucionaria de la modernidad industrial. Además se necesitaría mucha ingenuidad para imaginar que la entretención circense en que ha degenerado el deporte de nuestros días, chapoteando en su barrial de drogas, corrupción y escandalosa comercialización, podría de algún modo servir los propósitos morales de sus fundadores excepto como horrible advertencia. En cuanto a las agrupaciones de coleccionistas de cajitas de fósforos, los clubes de jardinería y las asociaciones filatélicas y bibliófilas,

\footnotetext{
${ }^{4}$ Hacia ese entonces, el único uso invernal para los pocos gimnasios techados existentes eran ejercicios calistécnicos de origen alemán y escandinavo, cuyo origen militar no se le escapaba a nadie. El inventor del basketball, el canadiense James Naismith era un graduado de la Universidad de McGill y del Colegio Teológico Presbiterianop y su expreso propósito fue precisamente "hacer el bien" incluso yendo más allá de su ministerio. Ver, C. Véliz, the New World of the Gothic Fox. Culture and Economy in English and Spanish America, University of California Press, 1994, pp. 132-150.
} 
pueden enorgullecerse con justicia de sus bajísimos niveles de delincuencia financiera, comparados con los del gran mundo comercial, reflejando incluso en esto los efectos normativos de la proximidad, la vergüenza, y el deshonor entre seres humanos ligados por lazos afectivos, aún cuando su objeto ostensible no pase más allá del mejoramiento de la raza gatuna o el cultivo de zapallos gigantes. Es sumamente difícil, sin embargo, pensar que incluso considerados en su totalidad, podrían estas organizaciones eventualmente vertebrar el renacimiento moral de la sociedad moderna.

Esto en cuanto al gran acierto. El gran error fue sin duda alguna la insistencia por parte de cuantos se ocuparon del problema, en considerar al entonces incipiente nacionalismo europeo como una ideología política de importancia tan minúscula como efímera.

Los yerros proféticos decimonónicos no fueron ni pocos ni menudos, y la ceguera respecto del carácter y proyecciones del nacionalismo no debe quedar archivada entre los menos importantes. Con la muy especial excepción de Moses Hess, quien estimó que un nacionalismo unido con el comunismo y el sionismo podría tener un futuro interesante, a ningún otro autor de nota se le pasó por la mente que ésta sería la ideología dominante en nuestro siglo veinte. ${ }^{5}$ Al contrario, en 1899, la Conferencia de La Haya impresionó a la opinión pública mundial con los que parecieron ser entonces firmes pasos hacia una paz duradera garantizada por sólidos acuerdos que trascendían enfáticamente las fronteras nacionales. Por ejemplo, la Conferencia acordó prohibir absolutamente y para siempre jamás el uso bélico de gases asfixiantes y de proyectiles lanzados desde globos. Pareció entonces que el establecimiento de un gobierno mundial era solo cuestión de tiempo y buena suerte. Esta impresión también se dejó sentir en 1907, cuando la reforma del Esperanto fue el tema principal de eruditas negociaciones en París para resucitar el agonizante idioma universal mediante la adopción de las variantes Ido y NovEsperanto y no fueron pocos los que abandonaron la Ciudad Luz convencidos que hacia fines del siglo veinte, el Esperanto renovado sería la lingua franca del globo terráqueo.

Pero lo que en realidad ocurrió durante el siglo veinte se apartó mucho de aquellos bien intencionados programas. No es posible ignorar, por ejemplo, 
que nunca antes ha albergado nuestro mundo tal cantidad de naciones, ciento ochenta y tantas, de las cuales la inmensa mayoría nació a la vida independiente durante los últimos cien años, y que es muy probable que varias más se sumarán a esta cifra impresionante antes que nuestro siglo pase a la historia. Tampoco se puede descartar este hecho macizo como una aberración, consecuencia de errores conceptuales que más bien temprano que tarde serán debidamente corregidos. Por el contrario, los actos de los muchos seres humanos que en otras distantes latitudes han estado dispuestos a morir por asegurar la independencia y soberanía de sus respectivas naciones, merecen ser tomados en serio.

A la evidencia cuantitativa debe agregarse una decidora dimensión cualitativa. Mientras en el pasado una existencia normal era virtualmente imposible fuera del ámbito de la cristiandad, hoy día un individuo puede vivir razonablemente bien sin domicilio permanente, sin lazos familiares e incluso sin religión. Lo que es imposible hoy día es una existencia totalmente exenta de documentación que certifique la afiliación formal a un estado-nación. Sin los consabidos "papeles", no es posible cruzar fronteras, adquirir propiedades, actuar profesionalmente, firmar contratos, ingresar a universidades o participar en actividades cívicas y, lo más importante, la única entidad que puede otorgar estos documentos legítimamente es el estado-nación. Esto no es ni bueno ni malo; no se trata aquí de prescribir, sino de describir lo que está ocurriendo frente a nuestros ojos, y esto es que las naciones no solo no se han esfumado, como lo presagiaron los pensadores decimonónicos, sino que se han multiplicado y, por primera vez en la historia de la humanidad, se las han ingeniado para establecer un régimen administrativo que incluye absolutamente a todos los seres humanos, sin excepción.

Recuerdo que por allá por las medianías del siglo, a un buen señor se le ocurrió botar su pasaporte y declararse "ciudadano del mundo", humorada que le significó pasarse los próximos cinco o seis años a bordo de un ferry del recorrido entre Dover y Calais puesto que ni Francia ni Gran Bretaña le permitían desembarcar. Luego de larga navegación, decidió volver al mundo de Sancho Panza, recuperó su pasaporte y se fue a su casa.

Ha sido asimismo durante este maltratado siglo veinte, que dos terribles conflictos mundiales infundieron nueva vida a la añeja sospecha que ve en el nacionalismo y la exacerbación de las diferencias culturales, especialmente lingüísticas, (he ahí el origen del Esperanto) la responsabilidad principal por las peores guerras modernas. Esta explicación quedó a mal traer cuando a 
mediados del siglo pasado cientos de miles de seres humanos que hablaban el mismo idioma y compartían la misma herencia cultural y religiosa, protagonizaron en la guerra de la secesión estadounidense lo que fue, hasta que la primera guerra mundial le arrancó el galardón, el conflicto más sanguinario de la historia. No está de más recordar que en aquella cruenta guerra civil, los Estados Unidos sufrieron 620.000 bajas, cifra superior al total de las bajas estadounidenses en Corea, Vietnam y las dos guerras mundiales. ${ }^{6}$ Es difícil defender la tesis que asigna al nacionalismo responsabilidad principal por las guerras modernas puesto que, desgraciadamente, abundan los ejemplos de feroces conflictos religiosos, civiles y dinásticos que hacen de tal afirmación una simpleza inaceptable.

El gran acierto decimonónico nos legó el problema de encontrar substitutos plausibles que ayuden siquiera a paliar los estragos morales y sociales resultantes de la disolución de la sociedad tradicional; el gran error nos deja enfrentados a una multitud de naciones lejanas de las esperanzas decimonónicas de gobierno mundial. Esta es la muy especial circunstancia que rodea el surgimiento de la mal llamada "globalización", término poco feliz que yo preferiría reemplazar por la frase "modernidad industrial", o incluso, por la muy respetable y precisa "Revolución Industrial".

El advenimiento de esta globalización de la modernidad industrial y sus productos y artefactos culturales, ha sido percibido por muchos como solución novedosa y eficiente para los dos problemas. En cuanto al primero, la esperanza radicaría en que la multiplicación y el perfeccionamiento de los medios de comunicación que la acompañan y caracterizan, harán del globo terráqueo una gran aldea, y volveremos a estar -como lo indicaba la definición de Peter Berger- rodeados de personas conocidas, pero esta vez conocidas al través del internet y su parentela de enseres electrónicos. Los adelantos en las comunicaciones, la "informática" y otras disciplinas derivadas, nos permitirán conocernos mejor y por ende, comprendernos mejor, asegurando así vidas prósperas y tranquilas.

Es tan imposible objetar a tales aspiraciones como melancólico verse obligado a observar que la inmensa mayoría de los asesinatos afecta a seres humanos que se conocen muy bien, sea por consanguinidad, matrimonio o lar-

\footnotetext{
${ }^{6}$ John Keegan, A History of Warfare, New York, 1993, p.356. Estas tristes características no escasean. Los conflictos internos en Perú y Colombia, por ejemplo, han cobrado más vidas humanas durante este siglo que todas las guerras internacionales que han ensombrecido la historia de estos países.
} 
ga amistad. Más aún, son raras las guerras de consecuencia que no han sido libradas entre países vecinos, y apenas hace falta agregar que no hay conflictos más cruentos y horrorosos que las guerras civiles en que los adversarios se conocen por lo menos tan bien como podrán algún día llegar a conocerse los entusiastas usuarios de los medios de comunicación electrónicos.

En cuanto al segundo problema, percibido como la proliferación de los nacionalismos, la expectativa es que el avance de la modernidad industrial borrará fronteras, disipará soberanías y diluirá localismos creando un ámbito cultural homogenizado y predecible.

Nada de esto parece inmediatamente plausible. Desde luego esta globalización no es $\tan$ novedosa como se pretende, puesto que nos ha visitado en el pasado bajo auspicios tan diversos como los de la helenización post-Alejandrina, la romanización imperial, y la cristiandad del medioevo, que acarrearon un bagaje tan respetable, aún cuando cualitativamente diferente, como el que ha generado la Revolución Industrial y sus secuelas. En cada uno de estos casos, la mayor parte de la humanidad entonces conocida sucumbió a la influencia de la cultura dominante de modos que no distan excesivamente de los que algunos temen está llevando hoy día a la homogenización de nuestro mundo. Cabe conjeturar, por ejemplo, si acaso durante los siglos helenísticos la proporción de la población mundial que asimiló los uso municipales atenienses, adoptó los órdenes clásicos en sus construcciones y usó la lengua griega para entenderse, no fue aproximadamente la misma proporción que más adelante se las entendió en latín, adoptó vestimenta romana, y acató las leyes de la metrópolis imperial, y la misma que mil años más adelante vivió de acuerdo con los preceptos morales y espirituales del cristianismo medioeval.

Pareciera aventurado aseverar hoy día que la proporción de los seis mil millones de habitantes del globo terráqueo que viaja en aeroplano, posee teléfonos celulares, consume alimentos envasados, mantiene correspondencia por e-mail, aprecia la musicalidad del rock-and-roll y gira contra bancos internacionales, es abrumadoramente mayor que lo fueron en su tiempo las proporciones helenísticas, romanizantes y cristianas que parecían ocupar todo el horizonte cultural del globo.

Tampoco parece persuasivo, ni como proyecto futurista ni como descripción de lo que está ocurriendo a nuestro alrededor, el argumento que sostiene que la globalización efectiva está haciendo del mundo una sola gran aldea. Por el contrario, el advenimiento de la modernidad industrial inauguró una 
temporada de internacionalismos tan bien intencionados como vacilantes que, lejos de extender los límites municipales del villorrio universal, no hicieron no confirmar con sus vacilaciones y fracasos la conveniencia de cada país independiente de continuar basando decisiones en un entendimiento riguroso de lo que constituye el interés nacional. No está de más agregar aquí que estas iniciativas internacionales suelen ser exitosas cuando las circunstancias son amables, prósperas y pacíficas, pero rara vez sobreviven encuentros con situaciones críticas emparentadas con soluciones mutuamente incompatibles.

Fue precisamente la Sociedad de Naciones la que inauguró esta temporada de vacilaciones tan razonables como prudentes en ligares como Manchuria, Abisinia, España y Checoslovaquia. Pero incluso antes de sufrir estos descalabros, la organización internacional ya se había ganado la severa crítica de José Ortega y Gasset que quien la describió como “...un gigantesco aparto jurídico creado para un derecho inexistente. Su vacío de justicia se llenó fraudulentamente con la sempiterna diplomacia, que al disfrazarse de derecho con-

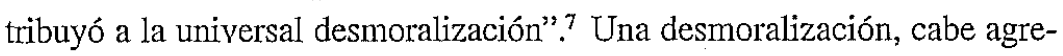
gar, que tomada conjuntamente con su debilidad política y militar y su excesiva burocratización, contribuyó en forma nada pequeña a su melancólico fin.

Los internacionalismos informales, sin embargo, no lo hicieron mejor y pocos ejemplos son tan decidores como el de los países escandinavos. No hace falta enumerar sus logros par afirmar que la opinión pública mundial considera a la agrupación escandinava como una de las más exitosas iniciativas de cooperación regional, una especie de modelo para el gran villorrio globalizado del futuro. Pero incluso allí la armonía y el espíritu de cooperación se esfumaron cuando la virtuosa agrupación se vio enfrentada con una crisis de verdad. En noviembre de 1939, solo días después de efectuarse en Estocolmo una reunión de jefes de estado de Suecia, Finlandia, Dinamarca y Noruega en la que su amistad y solidaridad eternas fueron solemnemente reafirmadas, la Unión soviética invadió Finlandia, pequeña nación que al mismo tiempo que echaba mano a las armas y se defendía con heroísmo ejemplar, pidió auxilio a la Sociedad de Naciones y a sus hermanos escandinavos. La organización mundial votó la expulsión de la URSS, que no se inquietó mayormente, e instó a Francia y Gran Bretaña a enviar ayuda. Ambas potencias acepta-

7 José Ortega y Gasset, "Epílogo para ingleses", aparecido .originalmente en la revista The Nineteeth Century, de julio, 1938; reproducido en La rebelión de las masas, $4 \pm$ a edición, Ediciones de la Revista de Occidente, Madrid, 1970, p. 279. 
ron hacerlo, pero se vieron efectivamente frustradas porque tanto Noruega como Suecia se negaron a autorizar el tránsito de las tropas y pertrechos necesarios a través de sus territorios, abandonando a Finlandia para que se las entendiera como pudiera con la agresión soviética. Para quienes estimen que esta excepción sólo confirma una regla, no está de más recordar que tres semanas después de la firma del tratado que puso fin a la ignominiosa "Guerra de Invierno", entre la Unión Soviética y Finlandia, tropas alemanas invadieron Dinamarca y Noruega, y nuevamente Suecia se las ingenió para mantener incólume una neutralidad más próxima a sus intereses nacionales que la tan celebrada solidaridad escandinava con sus países hermanos.

Experiencias como éstas continúan jalonando el historial de las agrupaciones mundiales y regionales con una inquietante secuela que va desde la corruptela de UNESCO hasta los bombardeos extra-legales efectuados por la OTAN, pasando por las modestas realizaciones económicas del Pacto Andino, la ineptitud de la Organización de Estados Africanos para prever o paliar las horrendas masacres perpetradas por sus miembros, los repetidos resbalones de MERCOSUR, y la apena encubierta rivalidad comercial transatlántica cuyas manifestaciones se multiplican a medida que se aleja la Unión Europea por su creciente y conflictivo aparato burocrático.

Nada de esto debe necesariamente ser interpretado como bueno o malo, más bien se trata de las consecuencias de un pragmatismo político internacional que durante el siglo veinte invariablemente ha valorado lo que se percibe como interés nacional por sobre aquel de un villorrio universal en gestación. En cuanto a resolver el problema de la disolución de la comunidad tradicional y sus consecuencias morales y sociales, me parece dudoso que iniciativas transnacionales como estas, con o sin beneficio de internet, posean autoridad moral susceptible de extenderse más allá de sus oficinas en Ginebra, Bruselas - Nueva York, y menos aún de establecer una presencia global que efectivamente ayude a crear la hipotética gran aldea bajo cuyos aleros podría renacer la comunidad Gemmeinschaft.

Aún más importante es la falacia de la homogenización que se presume será el resultado inevitable de la asimilación o desaparición de las culturas locales y regionales ante el avance incontenible de la marea cultural globalizante. Esta posibilidad, por ejemplo, tiene hoy día insomnes a los franceses que temen que en la ausencia de severas medidas para impedir la entrada de los artefactos culturales globalizantes, su incomparable patria francesa terminará 
siendo un mal remedo de Arkansas o California. Tales temores también parecen sumamente implausibles. Considérese, por ejemplo, lo que ocurrió durante los siglos romanizantes. Es indudable que el latín de los burócratas y soldados que viajaban de Roma a Dacia (la Rumania de nuestros días), era exactamente el mismo poderoso ingrediente cultural que otros soldados y burócratas llevaban consigo cuando viajaban a Hispania, pero la imposición en la periferia del imperio de un artefacto cultural tan vigoroso como la lengua latina no desembocó en nada que pudiera remotamente ser descrito como la homogenización lingüística de Rumania y España. Por el contrario, aunque obviamente emparentados con los resultados que conocemos. Algo similar ocurrió con el cristianismo medioeval que, en cuanto creencia religiosa, sería un error catalogar entre las más débiles de la historia, y que, impuesto uniformemente a través de la Europa, ha llevado a resultados de tal diversidad y latitud que incluyen desde los unitarios de Massachusetts a los coptos egipcios, desde los católicos de Roma a los ortodojos de Kiev, desde los calvinistas de Ginebra a los mormones de Utah y los pentecostales de Curepto y Combarbalá.

No está de más considerar aquí lo que ocurre con el jugo de limón, que de insípido no tiene nada, muy por el contrario, su sabor debe estar entre los más inconfundibles que es posible infligir al paladar. Es razonable pensar que, combinando con otros sabores más débiles o sutiles, tan vigoroso aporte no puede sino predominar, uniformando y homogenizando la mezcla resultante. Agréguese, sin embargo, jugo de limón a un vaso de leche, a un plato de ostras y a una copa de pisco, y los resultados serán esencialmente diferentes, la diferencia cualitativa proviniendo no del jugo de limón, sino que de las ostras, el pisco y la leche que, aún cuando ingredientes menos robustos, no desaparecen sino que modifican decisivamente al nuevo aporte. Así es como la cultura popular del mundo de habla inglesa, que es la que predomina indudablemente en esto de la globalización, puede mezclarse con la búlgaros, marroquíes, paraguayos y neozelandese, y en cada caso el resultado será diferente. Tan innegable como el avance incontenible de la modernidad industrial es que en cada región, cada país, cada familia o villorrio, el aporte globalizante está siendo permanentemente diversificado por el ingrediente local y uno, dos, y tres siglos de avasallamiento por la misma cacofonía de rigor, repletos además con las mismas inconfundibles vestimentas, automóviles, cines, bebidas gaseosas y expendio de pollos fritos de Kentucky, no bastarán para analogar a Varna, Valparaíso, La Guaira y Wollongong. 
Desde luego hay quienes discrepan de esta interpretación, notablemente aquellos regímenes políticos y religiosos tan amedrentados por la posibilidad que sus respectivos momentos culturales desaparezcan abrumados bajo una marea de hábitos y enseres perniciosos y globalizantes, que han intentado rigurosamente cerrar sus fronteras contra la infección. Apenas hace falta agregar que tales esfuerzos, notablemente la que pasó a la historia como "Revolución Cultural China", así como la revolución de los ayatollah, en Irán, no han tenido mucho éxito, habiendo demostrado, con el correr de los años, haber sido tan innecesarias para defender culturas perfectamente capaces de sobrevivir integradas a la cultura de la modernidad industrial, como ineficaces para detener su arrollador avance.

Todo esto sugiere que tanto la globalización de la modernidad industrial como el auge nacionalista contemporáneo, son menos solución y problema que objeto de descomunales malentendidos, que afectan a dos de los más importantes procesos formativos de la sociedad moderna y como tales, de especial interés para nuestra América Latina, donde ni los nacionalismos ni los intentos de incorporación a la vanguardia de la modernidad han tenido resultados notablemente exitosos. Más aún, como lo plantearía don Marcelino, tanto la oriundez de estos nacionalismos, como sus consecuencias, claman reconsideración desde el punto de vista de nuestra América Latina, puesto que las reflexiones que se han hecho hasta ahora han sido abrumadoramente acerca de estos fenómenos como se han dado en al Europa que les vio nacer.

Determinar el origen del nacionalismo es por lo menos tan importante como esclarecer que entre la multiplicidad de sus efectos, algunos de ellos indeseables, debe incluir el haber sido un factor necesario, aún cuando no suficiente, en el proceso de modernización industrial de los países del hemisferio norte que desde el siglo diecinueve ocupan la vanguardia económica y social del mundo.

Hoy día no cabe que la vigorosa tendencia igualitaria del nacionalismo emergente facilitó en su época procesos de movilización social que de otro modo no habrían encontrado lugar dentro de la estructura social de los regímenes dinásticos tradicionales 8 . Lo mismo no ocurrió en nuestros países, donde una extraordinariamente generosa siembra de nacionalismos decimonónicos

'Sobre estos aspectos, ver especialmente, Liah Greenfeld, Nationalism: Five Roads to Modernity, Harvard University Press, 1992; Ernest Gellner, "Nationalism and two Forms of Cohesion in Complex Societies", en Culture, Identity and Politics, Cambridge University Press, 1988, pp. 6-28. 
no produjo la anhelada cosecha de cambios sociales y progreso económico. Esta discrepancia va de la mano con otras, igualmente decidoras. Es evidente, por ejemplo, que los nacionalismos europeos tuvieron en sus orígenes un carácter enfáticamente introspectivo, que busco y encontró raíces históricas, folklóricas, y hasta mitológicas para explicar, justificar y alentar los sacrificios y tareas asociadas con la construcción de las nuevas nacionalidades. Francia no tuvo dificultades en establecer una genealogía que saludando a Juana de Arco y Carlomagno alcanzaba sin esfuerzo hasta la resistencia gala que tuvo a Julio César en apuros y, como era de esperar, los patriotas del risorgimento italiano hicieron buen uso de la proeza política y cultural de Roma, mientras que el nacionalismo alemán derivó de la rica tradición mitológica de los pueblos nórdicos. En Inglaterra, la búsqueda de antecedentes encontró hitos convincentes tanto en la Carta Magna como en la enfática política nacionalista de la monarquía Tudor y el simbólico retorno a la religión nacional que tan indeleblemente marcó la "Gloriosa Revolución" de 1688 y la instalación de Guillermo de Orange en el trono vacante. ${ }^{9}$ En Japón, fue precisamente la glorificación literaria del período a le Era Tokugawa que precipitó la restauración nacionalista Meiji y, paradójicamente, abrió el camino al industrialismo moderno con el famoso eslogan "Retorno a la antigüedad". Los ejemplos pueden multiplicarse y dejan abundantemente claro que los nacionalismos decimonónicos de la vanguardia modernizante en el hemisferio norte participaron de esta visión retrospectiva que encontró inspiración en un pasado ejemplarizante y alentador.

La experiencia de las nuevas naciones iberoamericanas fue notablemente distinta. Hay que recordar que éstas se forjaron no solo a la sombra de la "Leyenda Negra", que repudiaba todo lo ibérico a favor de modelos ingleses, franceses y estadounidenses, sino que también estuvieron influenciadas por el afrancesamiento del reformismo español con el cual miembros importantes del liderazgo intelectual y político del movimiento independentista tendían naturalmente a identificarse. ${ }^{10}$ Es así como a la conclusión de las largas y cruentas guerras de la independencia, la tarea de construir las nuevas nacionalidades se realizó con los ojos puestos en París, Londres y Nueva York.

9 Esta interpretación logró su más brillante manifestación en The History of England, de Lord Macaulay, publicada en 1848.1861, pero que aún mantiene su popularidạd habiendo logrado tres nuevas ediciones en formato de bolsillo de los Penguin Classics, 1968, 1979 y 1986. Ver tambiên, Gertrude Himmfarb, "Who Now Reads Macaulay?", en The New History and the old, Harvard University Press, 1987, p. 143-154. 
No asombra, por consiguiente, que el poeta argentino Esteban Echeverría haya elegido a Lord Byron y Víctor Hugo como patrones tutelares de sus famosas tertulias en la "Librería Argentina", ni que la constitución mejicana de Miguel Ramos Arizpe, en 1823, haya sido copiada casi palabra por palabra de la de los Estados Unidos, ni menos que los adalides del reformismo chileno hayan adoptado los nombres de sus émulos franceses, así Francisco Bilbao pasó a llamarse Vergniaud; Santiago Arcos; Marat; José Victorino Lastarría, Brissot; Domingo Santa María, Louvet; y Manuel Recabarren, Barbaroux. Pero estas son briznas al viento de la época, que se transformaron en vendaval cuando Sarmiento tomó la pluma. Todo el mundo sabe que la obra más leída de Sarmiento se titula Facundo, pero pocos recuerdan el subtítulo, $\mathrm{Ci}$ vilización y barbarie, y poquísimos se han tomado el trabajo de reflexionar acerca de sencillo significado. Para Sarmiento, la barbarie estaba encarnada en "Las tradiciones españolas y la conciencia nacional inicua, que han dejado (tras de sî) la Inquisición y el absolutismo hispano ..."; mientras que la civilización lo estaba en "la nación francesa (que) ha sido el crisol en que se ha estado elaborando, mezclando y refundiendo el espíritu moderno ..". Esta clara dicotomía justificaba el que la juventud de Buenos Aires se viera arrastrada por sentimientos de "fraternidad de intereses con la Francia y la Inglaterra (y) amor a los pueblos europeos... a la civilización, a las instituciones y a las letras que la Europa nos ha legado..": Es allí donde había encontrado "... apoyo contra la América... bárbara como el Asia, despótica y sanguinaria como la Turquía, persiguiendo y despreciando la inteligencia como el mahometismo" (sic). ${ }^{11}$ Muy pocas voces se hicieron oír que no compartían estos fervo-

${ }^{10}$ No está demás recordar que tanto Goya como liarte, Meléndez Valdés y Moratín y un sorprendente núme. ro de escritores y artistas igualmente afrancesados, recibieron con los brazos abiertos la instalaciôn de José Bonaparte en el trono español. Goya fue condecorado por "Pepe Botellas", por servicios a la monarquía bonapartista que incluyeron la preparaciôn de ura lista de cuadros españoles que a su entender deberían colgar en la capital de la jlustración. El famoso cuadro de los fusilamientos del 3 de mayo de 1808 , fue eje. cutado por Goya seis años después, quizás inspirado por la restauración de la monarquía. Ver Hufh Thomas. Goya: The Third of May 1808, Nueva York, 1972, pp. 69-70. Jose de San Martin adquirió sus idęas liberales y europeizantes durante los veintidos años que sirvió en el ejercito español antes de retomar a Buenos Aires en 1812; Bolivar vivió varios años en una Europa convulsionada por la empresa napoleónica, y cualesquiera sus reservas, pocos incidentes emarcaron tan profundamente como presenciar la coronación de Napoleón en Notre Dame, en $\mathbf{1 8 0 4}$. Bemardo O'Higgins, aún cuando menos afrancesado que otros, trajo consigo de vuelta a Chile, luego de sus años en Inglaterra, una profunda admiración por la cultura y las instituciones políticas de los isleños. " Domingo Faustino Sarmiento, Fucundo. Civilizaciôn y barbarie, Buenos Aires, 1972, p. 211; primera edición, 1845. Pasada la medianía del siglo, la marea europeizante alcanzó niveles de extraordinaria importancia y complejidad que culminó, por una parte, con la adopción generalizada, en México, Brasil, Argentina y Chile del ideario positivista de Auguste Comte, y por otra con la aventura bonapartista que terminó con la ejecución del emperador Maximiliano en Querêtaro. 
rosos nacionalismos extrovertidos, pero la de don Andrés Bello debe ser mencionada, puesto que aparte de su autoridad y enorme prestigio, tuvo un papel relevante en temperar los entusiasmos europeizantes y aportar una robusta dosis de sensatez a la consideración de estas materias ${ }^{12}$.

El estilo intelectual dependiente de estos nacionalismos latinoamericanos persistió en el siglo veinte bajo los nuevos signos revolucionarios que jalonaron nuestro historial, con melancólicos remedos de los populismos, anti-imperialismos, nazismos, socialismos, comunismos, anti-yanquismos y anarquismos importados que reiteraron en América Latina los desastrosos resultados obtenidos en Europa, incluso en Chile, donde los quijotescos nacionalismos de salón se estrellaron, con trágicas consecuencias, contra la infranqueable y socarrona sensatez criolla. Luego de siglo y medio de nacionalismos extrovertidos primero, y xenofóbicos y colectivistas después, lo menos que es dable observar es que ambos son recursos agotados en nuestras latitudes y circunstancias. Pero a esto hay que agregar que en América Latina en general, y enfáticamente en Chile, la modernidad industrial y sus efectos sociales sólo adquirieron gravitación importante como consecuencia de la Gran Depresión. Con anterioridad a 1929, ni la gesta emancipadora, ni los desórdenes revolucionarios, ni las reformas constitucionales y guerras internacionales afectaron mayormente la estructura de la sociedad, y el grueso de la población siguió viviendo aferrado a la tierra y sus faenas en vastas regiones inocentes de la influencia atomizante de la modernidad. No hubo necesidad, como evidentemente la hubo en la Europa decimonónica, de buscar apoyos morales o substitutos institucionales para mantener la cohesión y ordenamiento internos de la sociedad frente a los embates de la modernización industrial. Hasta antes de la crisis de 1929 todavía vivíamos rodeados de gente conocida. Solo ahora, durante las últimas décadas del siglo, los pasos vacilantes se han transformado en carrera desenfrenada, y la pausada disolución de los ordenamientos sociales tradicionales, en un acelerado desmantelamiento acompañado por

\footnotetext{
12 Pero la sensatez vino más tarde. En un artículo alabando precisamente una iniciativa educacjonal francesa, apareciendo en el Repertorio Americano de 1826, el eminente pensador describja al de España como "un gobierno que desde el reinado de fernando el Católico se halla en estado permanente de guerra con la civilización, que le ha disputado obstinadamente cada palmo de tierra, y que en las brevísimas treguas que ha hecho con ella, limitó siempre la suspensión de hostilidades a la Península. Enemigo jurado por los pueblos de Amërica?", en "Sociedad Parisiense de Enseñanza Elemental", Obras Completas de Don Andrês Bello, Santiago, 1893, volúmen XV, pp. 1*2.
} 
aumentos masivos de la delincuencia, el debilitamiento de la organización familiar tradicional, y un auge nefasto del tráfico y uso de drogas adictivas.

Es ilusorio pensar que la discutible transformación del mundo en una gran aldea va a resolver estos problemas. Es tan probable que esto ocurra, como que Chiloé adopte el Nov-Esperanto como lingua franca. Igualmente arriesgado sería confiar en la ayuda de los cansados substitutos -clubes, hobbies y deportes- que tan lealmente sirvieron originalmente como paliativos, ya sea por su envergadura insuficiente o por haber desvirtuado su propósito original, como es el caso de los deportes. Menos sensato aún es esperar que el apoyo y dirección que exige el momento provenga de los viejos nacionalismos, descalificados tanto por su carácter imitativo de episodios de la historia europea cuyos antecedentes aún no cruzaban el Atlántico, como por su origen, en los estratos europeizantes de la sociedad criolla, distantes de la inmensa mayoría de los chilenos. Es justo agregar aquí que en cuanto a eficacia doméstica para contrarrestar la marea disolvente del modernismo, quizás sean los cultos esotéricos y novedosas agrupaciones religiosas los más socorridos en la actualidad, no obstante factores excluyentes que necesariamente limitan su campo de acción.

Tales circunstancias, mi entender, han dejado abierta la puerta para la consideración de opción nacionalista que aún no entra en escena, y que pareciera tener buenas posibilidades de éxito, particularmente en Chile. Se basa esta opción en una sencilla hipótesis de trabajo que sugiere que si el nacionalismo fue un factor causa del modernismo industrial europeo y japonés, en Chile se empieza a perfilar como su posible consecuencia. Ahondando un poco, se puede argüir que la demanda por definiciones nacionalistas introspectivas, positivas y conducentes a una mayor y mejor cohesión social sólo puede descansar sobre una percepción generalizada de que las circunstancias del momento las exigen. Tal percepción está necesariamente ausente en el ámbito de sociedades tradicionales de corte Gemeinschaft, pero emerge gradualmente como consecuencia directa del avance de la modernización y sus procesos disolutivos de la sociedad pre-industrial. Esta relación causal ayuda a explicar el origen y persistencia del tranquilo, cortés, pacífico, pero férreo y acendrado nacionalismo contemporáneo de Suiza, Noruega, Singapur, Japón, Francia, Alemania, y los Estados Unidos, todos ocupantes bien establecidos de la vanguardia del modernismo, así como el hecho evidente que países como Bangladesh, Yugoslavia, Argelia, Indonesia, Filipinas, y Ruanda 
enfrenten las más arduas dificultades incluso para explicar a sus habitantes la necesidad de postergar localismos lingüísticos o religiosos a favor de un concepto de nación que para muchos de ellos es absolutamente incompresible.

No está fuera de lugar sugerir aquí, por ejemplo, que la valoración que ciudadanos de Oslo, Lausanne o Kyoto asignan a sus respectivos pasaportes, y las dificultades con que tropiezan quienes pretenden obtener ciudadanía en esos países, reflejan una apreciación de la nación elocuentemente compatible con la necesidad muchas veces milenaria de pertenecer a una agrupación tal que efectivamente contribuya a definir la condición humana y social de sus miembros. Estas calidades definitorias no pueden ser impuestas por la fuerza. No han sido nunca función del ejercicio del poder y es inconcebible que lo sean ahora. Por el contrario, tradicionalmente han estado asociada con la autoridad moral vinculada a la nacionalidad. En buen romance, sólo una opción nacionalista con la necesaria autoridad moral puede contribuir al establecimiento de nuevos patrones de cohesión social, acordes con las necesidades y oportunidades que ofrece la modernidad industrial. Una vez establecidos, estos patrones de conducta han demostrado poseer extraordinaria fortaleza y durabilidad, cualidades trágicamente puestas a prueba precisamente en la Europa que las vio nacer, y donde tanto las naciones veteranas como las más nuevas han sobrevivido las peores derrotas militares en la historia sin que se atenúen los lazos cívicos y morales que mantienes la cohesión y autoridad de la sociedad.

Aparte de las condiciones que afectan igualmente al resto de nuestro continente, Chile se encuentra en una posición adicionalmente favorable para tomar este camino. Desde luego nuestra insularidad es un factor nada minúsculo que establece paralelismos sugerentes con Japón y Gran Bretaña, dos naciones que siendo obviamente parte de sus respectivos continentes, han vivido una historia llena de pausas introspectivas que rara vez han resultado estériles. Por el contrario, ambas han demostrado una capacidad que no es difícil de asociar precisamente con su insularidad, de tomar lo que estiman necesario de otras partes del mundo, y hacerlo suyo sin por esto perder sus rumbos. Chile es una isla frente a las costas de América Latina, parte del gran continente, sin duda, pero lo suficientemente separado para tener una personalidad histórica inconfundible que a su vez plantea responsabilidades y metas que no es posible ignorar con impunidad. Mucho se ha escrito y conversado en los últimos años acerca del excepcionalismo chileno, y es difícil ignorar el he- 
cho que por lo menos durante siglo y medio hemos sido considerados atípicos o por lo menos extraños a lo que en el resto del continente se considera típico y familiar. Aquella conducta tan claramente alejada de la usual en el resto del continente, resultó en la construcción de una estructura institucional excepcionalmente eficaz y duradera que unos levantaron mientras otros seguían con la vista fija en bulevares parisinos y teatros londinenses; tan fija como hoy día la tienen algunos en una globalización de la cual esperan ayuda, inspiración y soluciones.

Aparte de consejos técnicos de importancia marginal, es ilusorio pensar que los problemas creados por el muy bienvenido avance de nuestra modernidad industrial serán resueltos desde fuera. No se trata aquí de sugerir un retorno al siglo diecinueve, sino de notar que la historia de nuestros peores momentos es la de sucesivos distanciamiento de los principios que vertebraron la proeza política formativa de la nacionalidad. En otras palabras, a diferencia de otros países de la región, Chile posee en su historia ejemplar un capital insuficientemente explotado que clama por ocupar el lugar que con tanta desfachatez y tristes resultados han estado llenando ídolos parisinos, ingleses, comunistas, nazistas socialistas y ululantes de diversos colores e inclinaciones.

La oportunidad de hacer uso de esta opción nacionalista no está exenta de obstáculos que no corresponden a un gobierno o a decisiones específicas, sino que reflejan una atenuación generalizada de la autoridad y responsabilidad morales frente a episodios que reclaman precisamente el ejercicio vigoroso de estos atributos. No está de más recordar aquí que la más popular de las virtudes de los monarcas que presidieron sobre nuestros orígenes indianos fue la de ofrecer una abundancia de justicia. Pues bien, esta generalización francamente folklórica y castiza es aplicable, por ejemplo, a la reacción gubernamental frente al innegable aumento de la delincuencia en los centros urbanos chilenos. No es menester hacer desfilar las estadísticas para demostrar este hecho; basta hacer notar que las entidades más quejosas, y con mucha razón, son las municipalidades, y que los aumentos han sido del orden del treinta por ciento en un año, involucrando en su mayor parte crímenes asociado al tráfico y consumo de drogas. Sin embargo, en lugar del justo rigor en la aplicación de las leyes existentes, la perc̀epción popular es una de repetidos incidentes de impunidad amén de reglamentos e instrucciones que resultan en penas risibles que virtualmente alientan la reincidencia de los infractores. Más aún, seguramente sin ninguna intención siniestra, pero senci- 
llamente como medidas de urgencia frente a la inacción de las autoridades, individuos y entidades han optado por contratar los servicios de guardias uniformados que aún cuando no portan armas y cooperan con el cuerpo de carabineros, su mera presencia es sintomática del debilitamiento de la autoridad central responsable por asegurar el buen ordenamiento de la sociedad.

Más inquietante aún es el melancólico fracaso de lo que indudablemente es una sucesión de gobiernos, en establecer un ámbito social en el cual los mapuches se sientan acogidos, respetados y protegidos como cualquier otro chileno, y no como ciudadanos de segunda clase. Los roces entre mapuches y autoridades nacionales tienen antecedentes tan complejos como añejos, pero cualesquiera la validez de las excusas y explicaciones, lo ocurrido refleja una persistente ausencia de voluntad ejecutiva para asumir plenamente las responsabilidades asociadas con el liderazgo democrático de una nación que se respete.

Ercilla no fue ni el primero ni el último en apreciar el temple de un adversario mapuche que ignoraba el concepto de la derrota y cuya porfiada guerra bien mereció la inmortalidad que le otorgara el poeta. Hay en La Araucana versos cuya dolorosa elocuencia es el mejor comentario acerca de mucho de lo que ha estado ocurriendo en nuestra patria durante los últimos años. Quién se atrevería hoy día a recitar en voz alta aquella descripción de nuestro Chile como una nación "de remotas naciones respetada por fuerte, principal y poderosa", cuando un ex Presidente de la República cumplió más de un año prisionero en un país extranjero? Tranquilizados los ánimos, archivadas las explicaciones y los informes médicos, y cualesquiera el resultado eventual de la ignominiosa intrusión española y la complicidad del laborismo británico, el hecho macizo que da en pié que doce meses después de cometido el ignominioso atropello, nuestras relaciones diplomáticas con ambos países continúan inalterables, como si nada anormal hubiera ocurrido, confirmando que nuestra política internacional se merece abundantemente la poco envidiable reputación de ser tan pusilánime como inepta cuando se trata de enfrentarse con desafíos de consideración.

Esta nueva opción nacionalista ofrece mejores esperanzas que la globalización, los clubes sociales, los cultos meditativos los conjuntos musicales y las agrupaciones gimnásticas, de responder positivamente a la justa demanda por un ámbito social latitudinario, bien ordenado y cohesionado que permita la realización de las múltiples oportunidades ofrecidas por los avances de la 
modernidad industrial. Para adelantar esta opción, será necesario escudriñar nuestro generoso pasado, formativo tanto de instituciones como de hábitos de conducta y programas de acción, en busca de una redefinición acorde con las circunstancias de nuestro tiempo de los principios sobre los que se fundamentó la construcción de nuestra nacionalidad. Será entonces muy difícil evitar que la autoridad política y moral derivada de tan noble introspección no gravite naturalmente hacia diseños políticos justos, eficaces y sólidamente enraizados en nuestro suelo patrio. 